\title{
El pensamiento jurídico de Ignacio Ellacuría Hacia la construcción de una teoría crítica de derechos humanos
}

\author{
Alejandro Rosillo Martínez, \\ Universidad Autónoma de San Luis Potosí, \\ México.
}

\section{Introducción}

Considerar a Ignacio Ellacuría como un pensador en el campo jurídico no es lo común; cierto es que lo más abundante de su obra está relacionado con la teología, la filosofía, la sociología y la política. No obstante, existen algunos artículos donde aborda el tema de los derechos humanos y el bien común: "El mal común y los derechos humanos"; "Hacia una conceptualización de los derechos humanos"; "Historización de los derechos humanos desde los pueblos oprimidos y las mayorías populares"; "Historización del bien común y de los derechos humanos en una sociedad dividida"; y "Universidad, derechos humanos y mayorías populares"2.

No hay que considerar como meramente coyunturales a estos artículos, es decir, como escritos que Ellacuría haya realizado tan sólo por su actividad política y por la importancia que tenían los derechos humanos en el contexto de la guerra civil en El Salvador. Esta aclaración no significa negar que la insistencia de nuestro autor de hacerse cargo de la realidad siempre estuviera presente en su pensamiento, sino que busca resaltar que su tratamiento del tema jurídico está en estrecha conexión con su pensamiento filosófico y teológico. En efecto, Ellacuría no realiza una simple repetición de la teoría dominante de derechos humanos, sino que los reflexiona desde la filosofía de la realidad histórica y del

1. Cfr. I. Ellacuría, Escritos filosóficos, Tomo III, UCA Editores, San Salvador, 2001.

2. Cfr. I. Ellacuría, Escritos universitarios, UCA Editores, San Salvador, 1999. 
pensamiento de la liberación. La materialidad de la historia, el logos histórico, el método de historización de los conceptos, la praxis histórica de liberación, entre otros conceptos, constituyen el marco teórico desde el cual Ellacuría colocaba el discurso de los derechos humanos al servicio del pueblo oprimido.

Desde esta perspectiva, el pensamiento de Ellacuría es un punto de partida para realizar una teoría crítica de derechos humanos; es decir, desarrollar una reflexión sobre estos derechos que responda mejor a la praxis de liberación de los pueblos. Es común observar que los grupos y movimientos sociales, en sus luchas, siguen reproduciendo el discurso liberal de los derechos humanos siendo que, en lo general, no coincide con su praxis ni sus objetivos. En otras palabras, se requiere construir una teoría de derechos humanos que responda a las luchas de liberación y no meramente a los procesos de liberalización. En este sentido, el objetivo de este artículo es presentar a grandes rasgos algunos puntos que el pensamiento de Ellacuría coloca en el debate para construir dicha teoría.

\section{Derechos humanos como herramienta de la praxis de liberación}

Dentro de su reflexión sobre la praxis, Ellacuría pone énfasis en las praxis históricas de liberación, es decir, en aquellas que actúan como productoras de estructuras nuevas más humanizantes. El proceso práxico de liberación es principalmente - aunque no exclusivamente- dialéctico en cuanto busca negar la negación de los seres humanos, y su avance afirmando lo positivo. La realidad histórica puede ser principio de humanización y de personalización, pero también puede serlo de opresión y alienación; esto porque "la praxis histórica no es reducible ni a las leyes del mundo natural ni a los saltos dialécticos de algún

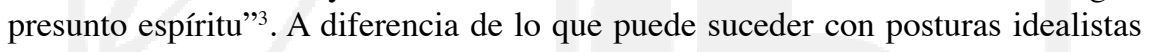
o mecanicistas de la historia, el mal y la injusticia en la historia no pueden ser legitimados ni justificados como unas necesidades lógicas en el desarrollo de una teleología o como partes de un devenir forzoso de la historia. Más bien el mal histórico es un límite real que se presenta como un desafío a la praxis de liberación. Desde esta perspectiva, Ellacuría valora el discurso de derechos humanos en términos positivos y de manera crítica, y busca comprenderlos como una herramienta para la lucha de liberación de los pueblos. En este sentido, la negatividad de la historia la expresa en términos de violación de derechos humanos: “¿Cuándo unas estructuras son evidentemente injustas? ¿Cuándo esas estructuras representan la institucionalización de la violencia? La respuesta es clara: cuando atentan gravemente contra los derechos fundamentales de la persona y cuando dañan peligrosamente el bien común del país. Quiere esto decir que, cuando la situación estructural de un país, el conjunto de su organización económica, de

3. A. González, "Prólogo", en I. Ellacuría, Filosofía de la realidad histórica, UCA Editores, San Salvador, 1999, p. 11. 
su organización jurídica y de su organización política, llevan durante un tiempo prolongado a la negación de los derechos fundamentales de la persona, tales como el derecho a la vida, el derecho a la alimentación y a la salud, el derecho a la educación, el derecho a la libertad, el derecho a un juicio justo, el derecho a no ser apresado injustamente y a no ser torturado, el derecho a la organización política, el derecho a la libre expresión, etc., entonces, estamos ante estructuras evidentemente injustas y ante la violencia institucionalizada"4.

Ahora bien, la liberación es un proceso a través del cual el ser humano va ejerciendo su libertad, y va haciéndose cada vez más libre gracias a su estructura de esencia abierta; un proceso que "en lo histórico, es un proceso de transformación, cuando no de revolución"5. La ventaja de la comprensión de la liberación por parte de Ellacuría, desde la estructura dinámica de la realidad, consiste en que constituye un concepto integral, que no se ubica sólo en el ámbito político o en el económico, ni tampoco enarbola una abstracción del ser humano. Se asume un proceso que busca concretar la libertad, creando las condiciones materiales y objetivas para su ejercicio. Comprendiendo así la liberación, el discurso de derechos humanos se vuelve un elemento importante para su consecución. Así, en la conceptualización que hace Ellacuría de la liberación, encontramos tres facetas donde claramente el instrumento jurídico-político que son los derechos humanos forma parte, asumido de manera crítica, de ellas. Estas facetas son las siguientes.

(a) La liberación de las necesidades básicas, cuya satisfacción es necesaria para una vida humana. "La liberación es, ante todo, liberación de las necesidades básicas, sin cuya satisfacción asegurada no puede hablarse de vida humana, ni menos aún de vida humana digna". Es lo que se debe llamar, según Ellacuría, "liberación de la opresión material". Los derechos humanos deben buscar satisfacer las necesidades humanas que posibiliten la producción y reproducción de vida; este debe ser su fundamento desde una perspectiva de la liberación.

(b) Liberación de las ideologías y de las instituciones jurídico-políticas deshumanizantes. "La liberación es, en segundo lugar, liberación de los fantasmas y las realidades que atemorizan y aterrorizan al hombre; en ella va incluida la superación de todas aquellas instituciones, sean jurídicas, policiales o ideológicas, que mantienen a los individuos y a los pueblos movidos más por el temor del castigo o el terror del aplastamiento que por el ofrecimiento de ideales y de convicciones humanas"7. Es la "libertad ante la represión".

4. I. Ellacuría, "Comentarios a la Carta Pastoral", en Escritos políticos, Tomo II, UCA Editores, San Salvador, 1993, p. 725. Cursivas mías.

5. I. Ellacuría, "En torno al concepto y a la idea de liberación", en Escritos teológicos, Tomo I, UCA Editores, San Salvador, 2000, p. 640.

6. Ibid., p. 645.

7. Ibídem. 
(c) Liberación personal y colectiva de todo tipo de dependencia que impide una autodeterminación plena. " $[\mathrm{H}] \mathrm{ay}$ que superar las dependencias, pues de poco sirve la libertad potencial si no puede romper las amarras del objeto que lo determina unívocamente, imposibilitándole a determinarse a sí mismo. Estas dependencias quitan libertad cuando están interiorizadas, pero el que provengan del interior no quita su carácter de anulación de la libertad: es lo que debería llamarse liberación de las dependencias (tendenciales, pasionales, atractivas, consumistas, etc.)"».

Esta manera integral de comprender la liberación supone un proceso de lucha por la justicia, que debe conducir al ejercicio auténtico de derechos humanos de todas las personas. De ahí que Ellacuría vea los derechos humanos desde los procesos de liberación y no desde la mera liberalización, entendida ésta como el proceso que apunta exclusivamente a la libertad subjetiva e individual; por eso denuncia las abstracciones de los derechos humanos que, aunque predicados para todos son ejercidos solo por unos cuantos, sobre una base material posibilitada por la explotación de la mayoría.

Cabe aclarar que Ellacuría no desprecia la libertad individual y subjetiva, ni mucho menos la capacidad creativa de la persona en la historia; su postura no es un colectivismo que niegue esta dimensión humana. Como mencionamos, uno de los elementos de la liberación es la libertad ante la represión, ante las realidades que atemorizan al ser humano, donde bien comprendidos están ubicados los derechos humanos, comúnmente llamados, de libertad. Donde no está de acuerdo es en considerar la liberalización - el proceso de individualización que nace desde el Renacimiento europeo - como un auténtico proceso de liberación integral de toda la humanidad: "Sin desestimar las virtudes de la liberalización (...), la liberación hace un planteamiento más material y más integral, en definitiva, más realista y más universalista".

Para Ellacuría, la realidad histórica no es creación de un macrosujeto, sino que es tarea de la humanidad misma. Por eso, no existe un paradigma único de liberación humana que sea válido en todo tiempo y lugar. Siempre será necesario discernir las formas, objetivos y contenidos de la posible praxis liberadora, pues esta se identifica con el proceso histórico mismo en cuanto este proceso es productivo y transformativo. Esta concepción pluralista del proceso de liberación no significa la negación de la realidad histórica como totalidad, sino que la misma praxis humana, y la historia como apropiación de posibilidades, implican ya en sí mismas la pluralidad. Tampoco significa negar la unidad de la humanidad, pues desde el proceso de liberación en su ámbito estructural la humanidad se comprende como parte del mismo phylum, pero para serlo y seguir siéndolo debe

8. Ibid., p. 646.

9. Ibíd., p. 645. 
entrar en un proceso integral de liberación, lo que requiere de una pluralidad en la praxis. Es decir, la misma dinamicidad de la realidad la hace plural y una.

\section{Comprender los derechos humanos desde la complejidad}

Uno de los últimos documentos publicados en la compilación de los Escritos filosóficos de Ellacuría son unos apuntes para un curso sobre el tema impartido en 1989, pocos meses antes de su asesinato. En este esquema se presentan diez afirmaciones que van "hacia una conceptualización de los derechos humanos" Aun con su carácter de escrito parcial y no publicado por el autor, es interesante conocerlo y analizarlo, pues en él podemos encontrar aplicaciones de su filosofía de la realidad histórica a la reflexión sobre los derechos humanos, además de una compleja conceptualización sobre ellos.

Es importante señalar que esta conceptualización no se inscribe en ninguna tradición liberal que centre su atención en la discusión sobre la distinción entre el orden jurídico y la moral. Tampoco se desarrolla bajo el presupuesto de que todo derecho es creación estatal, y por lo tanto, para Ellacuría un "derecho" es algo más que el mandato de la autoridad que genera un derecho subjetivo, pues no pretendía, así suponemos, realizar una teoría jurídica de los derechos humanos, sino comprenderlos como momentos ideológicos de la praxis histórica de liberación. Momentos ideológicos que, como se verá más adelante, corren el riesgo de ser ideologizados $\mathrm{y}$, en consecuencia, ser utilizados para fines distintos a la liberación.

La importancia que la realidad histórica tiene en la filosofía de Ellacuría le hace preocuparse de manera prioritaria por los derechos humanos desde su materialidad antes de elaborar una filosofía de contenido idealista, formal y abstracto que buscase precisar con exactitud el concepto de "derechos humanos". Por eso, no sería adecuado ni conveniente encasillarlo dentro de las corrientes "iusnaturalista" y "iuspositivista", o buscar insertarlo dentro de la discusión terminológica sobre los derechos, tan frecuente en el Primer Mundo, donde el debate se centra más en afianzar el sistema jurídico y estatal y los conceptos necesarios para su funcionamiento que en la realidad y en los procesos de liberación de subjetividades emergentes. Nuestro autor piensa los derechos humanos desde América Latina, donde el principal derecho - y también la mayor preocupación y la más urgente necesidad por satisfacer - de la mayor parte de las mujeres y los hombres es salir del estado de pobreza y explotación ocasionado por un capitalismo periférico y neocolonialista.

Desde la filosofía de la realidad histórica, el discurso de derechos humanos es pensado desde un paradigma de pensamiento complejo, no idealista, donde la

10. I. Ellacuría, "Hacia una conceptualización de los derechos humanos", en Escritos filosóficos, Tomo III, óp. cit., pp. 431-432. 
materialidad de la historia tiene preferencia ante cualquier intento de simplificación de estos derechos, es decir, de encerrarlos en el pensamiento de lo claro y distinto. En este sentido, para Ellacuría la expresión "derechos humanos", dentro de su complejidad, es algo que de alguna forma es "derecho", es decir, "algo que es debido y exigible, y que a la vez afecta radicalmente al hombre por ser hombre, aunque también a especificaciones más concretas de humanidad, como la de ser mujer o niño o ciudadano, etc." "1. A partir de esta comprensión, nuestro autor enumera lo que debe entenderse por derechos humanos.

(a) Los derechos humanos como necesidad. "Los derechos humanos son una necesidad de la convivencia social y política, son una necesidad socio-biológica y político-biológica, sin la que se hace inviable la especie y el modo social y político, en que la especie humana debe desenvolverse". Comprende los derechos humanos como una necesidad del ser humano, pero no desde una postura biologicista, sino desde la comprensión material de la historia. El ser humano sigue siendo un animal, pero con la peculiaridad de ser un animal de realidades, pues las cosas se le presentan no como estímulos, sino como realidades. Cuando Ellacuría habla de derechos humanos como una necesidad socio-biológica y político-biológica, está comprendiendo su fundamento desde las necesidades humanas, no sólo de las llamadas "necesidades básicas", sino de todas aquéllas que permiten al hombre desarrollarse como persona en comunidad. Se trata de la satisfacción de las necesidades que hacen viable a la especie humana, al phylum como tal, es decir, como animal de realidades. Esta viabilidad solo puede darse con la presencia de los otros dentro de la vida del individuo - en respectividad- que le habilitan en el modo humano de habérselas con la realidad. En este sentido es como deben comprenderse los derechos humanos: como la exigencia de satisfacción de las necesidades que hacen viables a la especie humana y a sus modos de convivencia social y política. Un conglomerado humano que imposibilita el acceso a los bienes a una parte de sus pobladores, que en su propia estructura genera la violencia que destruye vidas humanas, o cuyo concepto de bienestar pone en riesgo la viabilidad de la especie por razones ecológicas o por acciones bélicas, no puede ser considerada una comunidad humana donde se busque el cumplimiento de los de derechos humanos; su forma de "convivencia" no es capaz de satisfacer las necesidades socio-político-biológicas de sus miembros. Esta situación lleva a los seres humanos a establecer estrategias de lucha en busca de su sobrevivencia, aun pagando altas cuotas de represión; pero, insistimos, es una lucha que va más allá de la vida en puro sentido biológico: "Esta lucha por la vida contra la muerte, que es, en concreto, la lucha de la víctima contra su verdugo, puede darse en otros planos: el de la libertad, el de la justicia, el de la dignidad, el de la solidaridad; en definitiva, en el plano de la

11. Ibíd., p. 431. 
plenitud de la vida, que sin dejar nunca de ser biológica, transciende los límites de lo biológico"12.

(b) Los derechos humanos como exigencia física y moral. "Los derechos humanos son una exigencia, física antes que moral, no tanto de una naturaleza humana, abstracta e individual, sino de una esencia física, individual y específica, y del conjunto real de toda la humanidad y no del concepto de una humanidad abstracta". En conexión con la anterior definición, los derechos humanos parten desde la materialidad de la historia, la cual incluye al ser humano y a la humanidad en su totalidad. La exigencia de derechos humanos parte de lo físico de la realidad; la realidad se le impone al hombre y lo impele a tomar una opción, es decir, el ser humano debe hacerse cargo de la realidad. En este hacerse cargo, debe optar dentro de una serie de posibilidades; y para Ellacuría, este optar debe ir encaminado a una praxis de liberación, lo cual significa elegir aquello que posibilite el ejercicio de derechos humanos y que, por lo tanto, haga viable al phylum humano. En estructuras donde domina el mal común, la realidad no puede llegar a ser aquello que podría y debería ser, porque intereses minoritarios se lo impiden; es la propia realidad social y personal la que impele a la praxis humana a una transformación.

Es importante resaltar que en esta afirmación Ellacuría busca desvincularse de cualquier idealismo y iusnaturalismo abstracto que pregonen un "ser humano" universal, pues esta "representación abstracta" se trata en realidad de un tipo concreto de ser humano que se considera superior a los otros. No hay un "hombre abstracto", es decir, un ser humano anterior a la historia, que desde él se determine su contenido, su forma de desarrollo o su finalidad. La especie humana se va configurando en razón de la recepción y apropiación de posibilidades haciéndolas parte de su realidad. Por supuesto, en congruencia con la comprensión de la realidad histórica, abordar desde un humanismo concreto los derechos humanos no significa caer en una postura "relativista", sino comprender que la exigencia física y moral, aunque sea una, no destruye la pluralidad, ni los diversos y distintos procesos de liberación que los pueblos pueden seguir para hacer efectivas tales exigencias. Además, el criterio de verificación del cumplimiento de los derechos humanos debe estar en relación al conjunto real de seres humanos, donde se dan relaciones conflictivas, y no en referencia a una humanidad abstracta, la cual responde más a un $\log o s$ abstracto y a la que, por lo tanto, con facilidad puede dársele un uso ideologizado. Para Ellacuría, el ser humano no es "una generalidad unívoca y abstracta, que se repite multiplicadamente en los hombres concretos, sino, especialmente en lo que toca a los problemas del derecho, es una realidad escindida entre el que lo disfruta y el que lo padece y (...)

12. I. Ellacuría, "Historización de los derechos humanos desde los pueblos oprimidos y las mayorías populares", en Escritos filosóficos, Tomo III, óp. cit., p. 440. 
es una realidad dialéctica entre el fuerte y el débil, entre el señor y el esclavo, entre el opresor y el oprimido"13.

(c) Los derechos humanos como producto histórico. Para Ellacuría los derechos humanos no son algo ajeno a la realidad histórica y, por lo tanto, tampoco a la praxis humana. Por eso señala que "son un producto histórico, resultado de una praxis histórica determinada, reflejada en una conciencia colectiva, que los asume como rectores de la conducta pública". Desde esta concepción, se debe afirmar que derechos humanos, tal como los conocemos hoy día, son un producto surgido de un contexto concreto y preciso que se ha ido expandiendo por todo el planeta desde finales del siglo $\mathrm{XV}^{14}$. Sin embargo, reconocer que los derechos humanos son un producto histórico no significa encerrarlos en sus orígenes, es decir, encadenarlos a la civilización moderna capitalista creyendo que fuera de ésta no puede hablarse de aquéllos. La capacidad de la praxis humana para hacerse cargo de la realidad va mucho más allá, y nos posibilita repensar los derechos humanos superando la modernidad capitalista.

(d) Los derechos humanos como aspiraciones. Los derechos humanos, como parte de la realidad histórica, son abiertos y en constante cambio, y se van actualizando según los procesos de lucha de los pueblos en aras de su dignidad, buscando que su realidad humana dé más de sí. En este sentido, Ellacuría afirma que los derechos humanos "son aspiraciones naturales que se van actualizando históricamente, según la actualización de posibilidades y capacidades que se van dando desigualmente en distintos sectores de la humanidad, según vaya siendo su edad histórica".

Conceptuar los derechos humanos como aspiraciones naturales - es decir, aspiraciones con un fundamento biológico-ético, como comentaremos en el siguiente punto - parte de un "[h]umanismo histórico, dinámico, pero a la vez estructural, materialmente metafísico, "intramundano"" ${ }^{15}$, donde el acento de

13. Ibid., p. 435.

14. Al establecer el siglo XV como inicio del concepto histórico de derechos humanos, asumimos la postura de autores como Enrique Dussel e Immanuel Wallerstein que ubican en el descubrimiento de América el inicio del actual sistema-mundo, basado en el capitalismo y cuyas expresiones políticas más destacables son el Estado moderno y el discurso de los derechos. Cfr. E. Dussel, Historia de una política crítica, Trotta, Madrid, 2007; I. Wallerstein, Análisis de sistema-mundo. Una introducción, Siglo XXI, México, 2006. Esta opción la realizamos porque creemos que es más compatible con la visión de Ellacuría respecto a la crítica de los derechos humanos. Otra sería la discusión respecto a los inicios históricos de los derechos fundamentales en textos legales, que suele ubicarse en el nacimiento de las tres tradiciones liberales: la inglesa, la estadounidense y la francesa.

15. A. Salamanca, El derecho a la revolución. Iusmaterialismo para una política crítica, Universidad Autónoma de San Luis Potosí-Comisión Estatal de Derechos Humanos, San Luis Potosí, 2006, p. 7. 
la lucha por la justicia se vincula con las necesidades de vida del pueblo y no con las reivindicaciones; con esto se busca subrayar la materialidad de las prescripciones éticas (necesidades vitales) de la comunidad. Esta concepción nos posibilita abordar los derechos humanos desde distintas tradiciones culturales sin caer en un relativismo ético, pues a fin de cuentas los procesos de liberación van concretando las aspiraciones naturales que la realidad posibilita en un momento dado. Es decir, las necesidades no son equívocas (lo que sí serían las reivindicaciones, fundadas en un voluntarismo o idealismo jurídico arbitrario), pero tampoco se consideran las necesidades como una cuestión unívoca en el ser humano (lo que sería un materialismo vulgar o una metafísica no dinámica), sino que las necesidades del pueblo son fundamentadas bioéticamente, y la estructura dinámica del ser humano permite cierta pluralidad histórica de ellas y de sus medios de satisfacción.

(e) Los derechos humanos como prescripciones éticas. Ellacuría lleva al terreno ético la cuestión de derechos humanos, al afirmar que estos "son prescripciones éticas, obligantes en conciencia y que humanizan o deshumanizan a individuos, grupos o pueblos, según sea la habitud y la actitud respecto de ellos, así como de su cumplimiento o incumplimiento actuales". Insistimos que esta incursión de los derechos humanos al campo de la ética no puede tener como consecuencia comparar el pensamiento de Ellacuría con los moral rights de la tradición anglosajona, que se ubican en el horizonte liberal y del Estado moderno, y buscan encontrar una salida al legalismo positivista; en cambio, el horizonte de la filosofía ellacuriana es la praxis de liberación.

Esta perspectiva ética de los derechos humanos que propone Ellacuría coincide con el primer concepto que analizamos en esta sección: la fundamentación biológica de derechos humanos está en conexión con su comprensión ética. Al fundamentar la ética, Ellacuría rescata las notas biológicas que junto con las demás notas constituyen la sustantividad humana, que es a su vez una unidad estructural ${ }^{16}$. Pues si lo ético tiene que ver con la persona y el sujeto, no se puede ser ni persona ni sujeto más que de un modo constitutivamente biológico. Como hemos insistido, Ellacuría considera, siguiendo el pensamiento zubiriano, al ser humano como un "animal de realidades", en virtud de su inteligencia sentiente, lo cual le habilita para apropiarse de posibilidades por decisión y por opción: "Esta sujeción-a tener que apropiarse posibilidades por decisión para poder seguir viviendo y para poder dar respuestas a las situaciones en que está inmerso naturalmente, biológicamente, hace del hombre una realidad moral, o más exactamente, un animal de realidad moral" "17. Así es que la ética no puede desligarse

16. Cfr. I. Ellacuría, "Fundamentación biológica de la ética", en Escritos filosóficos, Tomo III, óp. cit., pp. 251-269.

17. Ibid., p. 256. 
de las raíces biológicas del hombre, y, por lo tanto, aquella es la respuesta humana a un problema radicalmente biológico: ser viables como individuos y como especie.

El cumplimiento o no de los derechos humanos - entendidos como prescripciones éticas - es lo que humaniza o deshumaniza a individuos, grupos, pueblos o a la humanidad misma. Pero deben comprenderse como prescripciones desde una ética con fundamento biológico, desde una ética de la vida, que busque, antes que otra cosa, satisfacer las necesidades que posibilitan al ser humano la apropiación de posibilidades, es decir, que abran la puerta a la producción y reproducción de su vida. Aunque se trata de una ética universal, se construye desde una comprensión de una totalidad que no anula las diferencias, pues la realidad humana no supone un modo unívoco o predeterminado de realización, sino algo abierto a la creatividad y a la exigencia histórica.

(f) Los derechos humanos como valores. "Los derechos humanos son valores que la colectividad (en su extrema, la humanidad) va estimando como algo indiscutible, que se da por aceptado, al menos en su significado teórico". El tema del consenso comunitario y mundial por los derechos humanos es considerado como un dinamismo positivo por Ellacuría; no obstante, este consenso debe ser historizado para asumir críticamente el desde dónde se va instaurando el "consenso mundial". Para Ellacuría no es lo mismo un consenso por los derechos humanos realizado desde las grandes mayorías populares o desde los grupos sociales anticapitalistas que el consenso elaborado desde las grandes potencias del planeta; su para qué y su por qué son muy distintos en la realidad por más que formalmente se predique lo mismo.

(g) Los derechos humanos como ideales utópicos. El tema de la utopía es importante en el pensamiento de Ellacuría, pues su filosofía de la realidad histórica así lo requiere. La realidad histórica es procesual y dinámica, y en ella se nos da el campo abierto de las máximas posibilidades de lo real. Pensar los derechos humanos desde la filosofía de la realidad histórica hace necesario explotar su dimensión utópica, es decir, incorporarlos en un horizonte utópico. Por eso, Ellacuría señala: "Los derechos son ideales utópicos que presentan algunos individuos, grupos o pueblos, como motores de una permanente humanización del individuo y de la humanidad". Esto supone que los ideales nacen desde la praxis humana, esto es, son esbozados desde las mismas acciones humanas y se dirigen a ellas mismas como motores de procesos de liberación. Esta dimensión tiene un carácter dialéctico, pues la denuncia de las situaciones de violación de derechos humanos y la utopía se potencian mutuamente. Es necesario un horizonte utópico para que se dé la toma de conciencia de que algo puede ser superado; pero también se requiere una constatación del origen estructural de la negación de derechos humanos (de su privación y violación), para que dicha toma de conciencia adquiera la forma de un auténtico dinamismo de lucha y de exigencia 
real de bienes. Por eso, "la denuncia sin utopía es, hasta cierto punto, ciega, pero la utopía sin denuncia es prácticamente inoperante, más aún, eludidora del compromiso real"18.

(h) Los derechos humanos como momentos ideológicos. La función liberadora de la filosofía se expresa a través de la crítica que debe estar orientada a desenmascarar lo que de falso e injusto contiene la ideología dominante como momento estructural de un sistema. Sin embargo, la prioridad la tendrá la crítica a la ideologización, pues ésta puede ser reproducida no solo por los aparatos teóricos, sino también por estructuras, ordenamientos y relaciones sociales. Frente al fenómeno de la ideología es donde se define, en buena medida, la función crítica de la filosofía. Este aspecto de la filosofía ellacuriana tiene una importante resonancia en el campo de los derechos humanos, al considerarlos como "momentos ideológicos de una determinada praxis, que pueden convertirse en momentos ideologizados cuando ocultan o protegen intereses y privilegios minoritarios". Esto lo desarrollaremos un poco más en el siguiente apartado.

(i) Los derechos humanos como derechos positivos. Señala Ellacuría que "[1]os derechos humanos son derechos positivos, otorgados y sancionados por las instancias capaces de hacerlo, especialmente los Estados e instituciones internacionales". La positivación de los derechos humanos no es algo menor para Ellacuría. Este hecho debe considerarse como el uso de la fuerza del Estado para satisfacer las necesidades socio-político-biológicas del pueblo; se trata de la dimensión ética de la acción del Estado. Dentro de este uso, la fuerza del Estado estaría justificada, pues de lo contrario sería en realidad mera violencia y, en los casos más grandes, una violencia estructural; señala Ellacuría: "El Estado que realmente sirve al bien común, esto es, al bien de todos y especialmente al bien de la mayoría, tiene los suficientes recursos para imponer, a la larga, el orden justo. No necesita entrar en la dinámica del dar y recibir golpes como si fuera una facción más del espectro político" ${ }^{19}$.

(j) Los derechos humanos como convenciones y contratos. El último concepto que otorga Ellacuría es que "los derechos humanos son convenciones y contratos sociales y políticos, que hacen los individuos entre sí y con el Estado, y los Estados entre ellos". Al parecer, Ellacuría asume en esta definición elementos de la tradición contractualista, que busca fundamentar los derechos humanos en el "contrato social", sea este entendido como una hipótesis o como la construcción de un consenso basado en el funcionamiento de instituciones democráticas. No obstante, de manera semejante que en el inciso anterior, esta comprensión contractualista debe estar en función de la dimensión ético-biológica del ser

18. I. Ellacuría, "Historización de los derechos humanos desde los pueblos oprimidos y las mayorías populares", óp. cit., pp. 438-439.

19. I. Ellacuría, "Comentarios a la Carta Pastoral”, óp. cit., p. 716. 
humano. No puede pactarse, ni ser elemento de un contrato social, aquello que vaya contra las necesidades del pueblo y de la humanidad, y contra las condiciones de vida y su reproducción; aunado a esto, quienes están en condición de víctimas del sistema no están en las posibilidades reales de formar un consenso justo. Además, la fundamentación metafísica del "contrato social" que supone la existencia de un individuo sin concreción histórica, desde el cual se predican ciertos derechos, es insuficiente para defender la vida y la dignidad de los seres humanos. Ellacuría es claro al rechazar esta doctrina: "Cuando Hobbes en 1651 escribía en Leviatán que son tres las causas de las luchas entre los hombres y que las tres están inscritas en la naturaleza humana: la inseguridad, la competencia y el deseo de gloria, estaba describiendo más la experiencia del hombre occidental emergente que algo necesariamente ínsito en la naturaleza humana" ${ }^{20}$. Además, este "contrato social" también es peligroso por su idealismo fácilmente utilizable para los intereses del capitalismo; de ahí que Ellacuría rechace todo humanismo abstracto por ser manipulable para la explotación de otros seres humanos: ningún ser humano en concreto puede ser usado como medio para conseguir que el ser humano en abstracto sea tomado como fin en sí mismo ${ }^{21}$.

El análisis de las diversas conceptualizaciones sobre derechos humanos que realizó Ellacuría poco antes de su muerte nos permite afirmar que, desde su filosofía de la realidad histórica, asumió las distintas dimensiones que estos derechos tienen como parte de la praxis humana. Comprendió su aspecto histórico, social, jurídico-positivo y ético, sobre el fundamento de la producción y reproducción de la vida del pueblo, es decir, desde la satisfacción de las diversas necesidades que hacen viable al phylum humano, sea como personas o como sociedad y especie.

\section{La crítica a la ideología de los derechos humanos}

La crítica a la ideología de los derechos humanos es otro punto que debemos considerar para la construcción de una teoría de derechos humanos desde la praxis de liberación. En este sentido, una de las propuestas más interesantes de Ellacuría es el método de historización de los conceptos, a través del cual se busca descubrir el uso interesado de los conceptos que justifican un orden establecido; es decir, desvelar aquellas falsedades que han sido institucionalizadas y promovidas como verdaderas y que, como parte de las fuerzas históricas, han afectado el desarrollo de la historia.

20. I. Ellacuría, "Utopía y profetismo", en Mysterium liberationis. Conceptos fundamentales de la teología de la liberación, Tomo I, UCA Editores, San Salvador, 1993, p. 420.

21. Cfr. I. Ellacuría, "El testamento de Sartre", en Escritos filosóficos, Tomo III, óp. cit., pp. 319-332. 
Un concepto historizado se contrapone a un concepto abstracto y universal, y busca situar el contenido del concepto en relación con la praxis histórica y descubrir cómo opera en el proceso social ${ }^{22}$. Es decir, es aquel concepto que responde en sus contenidos a la realidad histórica; esto es así porque se entiende por concepto un momento ideológico de la praxis humana. Al surgir de situaciones concretas, los conceptos históricos adquieren diversos significados según sea la situación en la cual se proclaman como verdaderos; son conceptos operativos, pues su verdad se puede verificar en sus resultados y su contenido debe ir cambiando aunque siga manteniendo su sentido esencial.

La historización como método tiene en cuenta que toda acción e interpretación se deben a las condiciones reales de una sociedad y a los intereses sociales que la sustentan, y tiene como propósito medir no "cuál es un determinado sentido crítico, sino cómo ha podido surgir realmente un determinado sentido a partir de un desde dónde físico" 23 . Al ser momentos ideológicos de la praxis humana, los conceptos pueden convertirse en momentos ideologizados cuando ocultan o protegen intereses y privilegios minoritarios ilegítimos e injustos. Es así como la historización hace una función de desideologización, pues cuestiona y desfundamenta aquellos conceptos que, por ejemplo, presentados como inmutables e invariables por una supuesta naturaleza humana, son negación, en la realidad, de lo que dicen ser. En efecto, el método de historización responde a la necesidad de hacer históricos unos conceptos abstractos y universales que, probablemente, pueden estar protegiendo los intereses de los sectores privilegiados de una sociedad. En este sentido, Ellacuría señala que "mostrar qué van dando de sí en una determinada realidad ciertos conceptos es lo que se entiende por historización" 24 .

Dentro de una praxis de liberación, es necesario historizar la conceptuación formal de derechos humanos, pues se corre el riesgo de ser ideologizada; es pensarla desde un logos histórico. Ellacuría reconoce el valor del planteamiento formal de derechos humanos, pero sostiene la insuficiencia de estos enfoques formales, ya que sus aspectos positivos tienen que ser reasumidos dentro del proceso de historización o, de lo contrario, serán postulados abstractos sin ninguna incidencia en la realidad. Se debe ser consciente de que los derechos humanos son momentos ideologizados de la praxis humana y por eso necesitan de su historización. Si no, son solo una abstracción sobre la cual se predican principios que nada tienen que ver con la realidad, y aunque esos principios sean parte

22. Cfr. I. Ellacuría, "La historización del concepto de propiedad como principio de desideologización”, en Escritos políticos, Tomo I, UCA Editores, San Salvador, 1993, p. 591 .

23. I. Ellacuría, "Hacia una fundamentación del método teológico latinoamericano", en Escritos teológicos, Tomo I, óp. cit., p. 216.

24. I. Ellacuría, "La historización del concepto de propiedad como principio de desideologización”, óp. cit., p. 428. 
de su "deber ser", el darlos por asentados sin realizar su verificación histórica conlleva a un uso ideologizado.

La necesidad de historizar los derechos humanos surge de su complejidad, pues en ellos no solo confluyen la dimensión universal del ser humano con la situación realmente distinta en la que desarrollan su vida los hombres, sino que además con facilidad son utilizados ideológicamente no al servicio del ser humano y su producción de vida, sino de los intereses de ciertos grupos de poder. La historización de los derechos humanos, dice Ellacuría, no consiste formalmente en contar la historia del concepto, ni tampoco relatar la historia real connotada, sino que sigue las pautas del método de historización de los concep$\operatorname{tos}^{25}$ : (a) la verificación práxica de la verdad-falsedad, justicia-injusticia, ajustedesajuste que se da del derecho proclamado; (b) la constatación de si el derecho proclamado sirve para la seguridad de unos pocos y deja de ser efectivo para los más; (c) el examen de las condiciones reales, sin las cuales no tienen posibilidad de realidad los propósitos intencionales; (d) la desideologización de los planteamientos idealistas, que en vez de animar a los cambios sustanciales, exigibles para el cumplimiento efectivo del derecho y no solo para la afirmación de su posibilidad, se conviertan en obstáculo de los mismos; y (e) la introducción de la dimensión tiempo para poder cuantificar y verificar cuándo las proclamaciones ideales pueden convertirse en realidades o alcanzar, al menos, cierto grado aceptable de realización.

La historización exige buscar la raíz más profunda de la negación de los derechos humanos, que debe verse desde dos polos: la realidad negada, que no puede llegar a ser aquello que podría y debería ser precisamente porque se lo impiden, y la realidad negadora, sea personal, grupal, estructural o institucional. Es este un proceso dialéctico donde la teoría interviene para descubrir la historicidad del derecho negado y deseable, y donde la praxis debe ir dirigida al establecimiento de estructuras e instituciones justas para lograr superar la realidad negadora de dicho derecho. Es la lucha por los derechos humanos como expresión más clara de una conciencia madura al respecto.

Con estas bases, y en coherencia con su fundamentación político-biológica, para Ellacuría queda claro que la historización de los derechos humanos desde los pueblos oprimidos muestra que el problema radical es "el de la lucha de la vida en contra de la muerte, es la búsqueda de lo que da vida frente a lo que la quita o da muerte" ${ }^{26}$. Una lucha contra la muerte en diversos grados - social, personal, estructural - no solo restringiendo la vida a su dimensión biologicista, sino a todo tipo de vida, y que se expande a diversos planos: el de la libertad,

25. Cfr. I. Ellacuría, "Historización de los derechos humanos desde los pobres oprimidos y las mayorías populares", óp. cit., p. 434.

26. Ibíd., p. 439. 
el de la justicia, el de la dignidad, el de la solidaridad, etc. Por otro lado, la lucha de la vida en contra de la muerte constituye un principio fundamental para plantearse el problema de los distintos derechos humanos y su jerarquización. Ellacuría llama la atención acerca de que en los hechos se da el disfrute de unos derechos no fundamentales (y muchas veces superfluos) por unos pocos, y estos se constituyen en una causa real para que la mayor parte se vea privada o desprovista de sus derechos humanos, de aquellos que aseguran la vida y su reproducción: "No podrían los pocos (grupos humanos o países) disfrutar de lo que consideran sus derechos, si no fuera por la violación o la omisión de esos mismos derechos en el resto de la humanidad. Sólo cuando se acepte esto, se comprenderá la obligación de los pocos a resarcir el mal hecho a los muchos y la justicia fundamental al exigir lo que realmente les es debido. No puede darse la muerte de muchos para que unos pocos tengan más vida; no puede darse la opresión de la mayoría para que una minoría goce de libertad"27.

Para Ellacuría el enfoque liberal de los derechos humanos es limitado. No porque rechace los frutos de las luchas por la libertad, ni su contribución a la construcción de sociedades justas, sino porque es insuficiente y su discurso se ha vuelto un instrumento ideológico funcional para la estructura capitalista; aunque el liberalismo político es diferente ideológicamente, e intenta conservar cierta autonomía, en relación con el liberalismo económico, en las condiciones materiales de la actual configuración de la realidad histórica, muchos de sus presupuestos son utilizados interesadamente para impedir la superación de estructuras injustas: "La libertad burguesa, que subyace en muchos de los anuncios de la libertad, está fundada en la propiedad privada, y más en concreto en la riqueza; sin el desequilibrio de unos pocos que tienen mucho y de unos muchos que tienen poco, apenas puede hablarse de libertad" ${ }^{\prime 2}$. Por lo tanto, no basta la liberalización para conseguir la libertad, sino que son necesarios diversos procesos de liberación que se constituyan en la negación superadora del mal estructural ${ }^{29}$.

La verificación de los derechos humanos debe realizarse no desde lo que se dice, sino desde las prácticas reales de los pueblos ${ }^{30}$; es decir, no basta el discurso ni la implementación de derechos humanos en textos legales nacionales

27. Ibíd., p. 442.

28. I. Ellacuría, "En torno al concepto y a la idea de liberación", óp. cit., p. 644.

29. Señala Ellacuría: "Siempre, pero en el mundo actual de forma más sutil, hay múltiples formas de anular la autodeterminación o de reducirla a la respuesta, aparentemente libre, a solicitaciones y presiones que vienen de dentro o de fuera. Hay el peligro de una perpetua esclavitud personal, por más que se piense que se ha elegido libremente al señor o al poder de quienes se quiere ser esclavo" (ibíd., p. 641).

30. J. A. Senent, "Los derechos humanos desde los pueblos oprimidos", en R. Cardenal y J. Sobrino (coords.), Ignacio Ellacuría. Aquella libertad esclarecida, Sal Terrae, Santander, 1999, p. 165. 
o internacionales, debido a que se corre el peligro de que los derechos humanos se reduzcan a una normatividad absoluta y abstracta, independiente de toda circunstancia histórica, y que probablemente consista en una forma velada de defender lo ya adquirido o adquirible en el futuro por los más fuertes.

\section{Repensar la historia de los derechos humanos}

La filosofía de la historia de la modernidad, surgida a partir del pensamiento de Herder y Kant y conducida a su máxima expresión por Hegel y Marx, concibe la historia como desarrollo, como un desenvolvimiento de lo que al principio potencialmente sea en la naturaleza del hombre, en la lógica del Espíritu Absoluto o en la constitución dialéctica del mundo material. No hay duda de que estas concepciones de la historia buscaron guiar la emancipación del ser humano. Sin embargo, muchos de estos autores terminaron desconfiando del ser humano y buscaron otra instancia que asegurara el progreso de la historia. Entonces, la novedad histórica desaparece y también la responsabilidad ética frente a la historia. La historia se vuelve un proceso racional y teleológico, y por lo tanto se trataría de un proceso unitario. Por eso, esta concepción de la historia es eurocéntrica, pues se considera a Europa como la punta de lanza del proceso. Esta visión está presente en la lectura oficial sobre los derechos humanos como un desarrollo histórico lineal, dividido en generaciones y procesos de generalización y especificación.

El pensamiento oficial de occidente no evalúa honradamente su pasado ni su progreso. Si no fuera por las consecuencias que esto conlleva, parecería que hay una carga de inocencia. Ellacuría critica a los teóricos del "progreso" porque enfocan "la cuestión sin percatarse que el 'progreso' es una abstracción"31.

La idea de derechos humanos sufre de esto, en especial cuando se utiliza su historiografía como un instrumento ideológico para justificar el capitalismo, presentándolo como "un capitalismo bueno", que con el paso del tiempo y la expansión de los derechos (primera, segunda, tercera, cuarta generaciones) se ha vuelto "menos salvaje". Esta forma de ver la historicidad de los derechos humanos está influenciada por la filosofía de la historia de la modernidad. Los derechos humanos son concebidos como productos racionales que, desde su nacimiento formal en las luchas burguesas del siglo XVIII, tienen contenidos en sí mismos todo lo que han de dar. Lo único que se necesita es que pasen de la potencia al acto a través de la historia. Así es como se lee su historia como un proceso lineal sin contradicciones: los derechos sociales no son considerados como la afirmación de un sector que se veía explotado por aquellos sectores que se habían empoderado a través de la afirmación de los derechos liberales, ni los derechos culturales y de los pueblos se comprenden como el empoderamiento

31. I. Ellacuría, "Progreso y revolución”, en Escritos teológicos, Tomo I, óp. cit., p. 268. 
de los conglomerados a quienes el colonialismo les ha negado su dignidad. Se afirma que solo son procesos contenidos en la propia naturaleza o en la racionalidad de los derechos humanos, y se trata de procesos de generalización y de especificación de los mismos derechos originados en el siglo XVIII. Lo que se termina sosteniendo es que el sujeto de los derechos humanos es el ser humano en abstracto, trátese de los derechos liberales, de los derechos sociales o de los derechos culturales, y se relega la importancia de la praxis y la creatividad de la persona y comunidades concretas para comprender el avance de la historia. Paradójicamente, este liberalismo del sujeto abstracto termina siendo funcional al totalitarismo del mercado, pues desde la manera en que está estructurado el actual sistema-mundo, y considerando la materialidad de la historia, la única libertad plena es la de quien pueda ejecutarla como libertad en el mercado. Por medio de dicho humanismo abstracto, se acaba por inscribir a los derechos humanos en una instancia suprahumana, semejante al Espíritu Absoluto de Hegel; pero no es esta la visión de Ellacuría.

En la concepción de historia de Ellacuría hay un rechazo a cualquier presunto macrosujeto que la guíe. Siguiendo a Zubiri, supera la concepción de la historia construida bajo los presupuestos aristotélicos de potencia y acto, donde la historia no es otra cosa que una actualización de potencialidades contenidas desde el principio por un sujeto o una substancia universales. La historia es entendida por Ellacuría desde la praxis humana y los conceptos de capacitación y posibilitación. Es el ser humano en su integralidad, a través de la praxis históri$c a$, quien toma sobre sus hombros el hacerse cargo de la realidad. De ahí el rechazo a colocar los derechos humanos fuera de la materialidad de la historia, sin que esto signifique un acotamiento a la creatividad humana. La praxis histórica es una praxis real sobre la realidad, y este debe ser el criterio último que libere de toda mistificación: ya sea la mistificación de una espiritualización que no tiene en cuenta la materialidad de la realidad, o una mistificación de la materialidad que tampoco tiene en cuenta su dimensión trascendental. Este rechazo a una comprensión abstracta de los derechos humanos lleva a Ellacuría a comprender, más allá del liberalismo, la auténtica dinámica de la conquista de derechos: "Podría decirse que el liberalismo (...) busca ofrecer igualdad de oportunidades para todos los individuos y todas las tendencias. Pero de hecho esto no es así y el (...) mínimo ejercicio de historización muestra que las libertades y sus condiciones no se regalan, sino que se conquistan en un proceso histórico de liberación" "32. En efecto, desde esta comprensión de la historia, se puede realizar una fundamentación popular y sociohistórica de los derechos humanos, con base en la satisfacción de las necesidades, más acorde con la urgencia de justicia para el Tercer Mundo.

32. I. Ellacuría, "Utopía y profetismo”, óp. cit., p. 417 (cursivas mías). 
La historia es concebida, entonces, como un proceso discontinuo y sometido a retrocesos y estancamientos, de adquisición de capacidades por parte del sujeto humano y de actualización de posibilidades en la realidad social e histórica. Este proceso no se presenta como algo necesario, con lógica interna o con un telos que marque la superioridad moral de una civilización o cultura. Se trata de un proceso contingente, frágil y sometido a pérdidas y retrocesos. La historia es siempre un proceso creativo y abierto: "El destino de la historia es algo que la historia se va dando a sí misma: se va dando sus propias posibilidades, se va dando sus propias capacidades (...) y se va dando - o al menos se puede llegar a darsu propia figura histórica" ${ }^{33}$. En este sentido, lo que define una época histórica es la altura procesual, es decir, el determinado sistema de posibilidades que en el proceso de la realidad histórica condiciona el carácter de las acciones humanas.

Esta concepción de la historia es más apta para comprender el desarrollo de los derechos humanos. Desde ella, la clásica división en "generaciones" ayuda a tomar conciencia de que los derechos humanos no son algo estático, sino dinámico en el seno mismo del occidente, producto de conflictos y surgimientos constantes de nuevas subjetividades, lo cual permite comprender mejor que desde otras culturas y civilizaciones pueden ser cuestionados en su pretendida universalidad abstracta.

Defender las posturas idealistas de los derechos humanos, abstractas y universalistas, significa no comprender el carácter abierto y procesual de la historia. Es desconocer la capacidad del ser humano de repensar constantemente el mundo en que vive, de asumir las posibilidades y capacidades que un momento histórico le permite.

\section{El uso alternativo de los derechos humanos}

Otro tema que coloca en la discusión el pensamiento de Ellacuría respecto a los derechos humanos es la posibilidad de hacer un uso alternativo de ellos. Nuestro autor entiende, en un primer momento, los derechos humanos como algo debido cuya carencia o disfrute condiciona seriamente el propio desarrollo humano; son la concreción del bien común, o en sentido negativo, la superación del mal común: "Una consideración de los derechos humanos desde esta perspectiva del mal común dominante los mostraría como el bien común concreto, que debe ser buscado en la negación superadora del mal común, que realmente se presenta como una situación en (...) que son violados permanente y masivamente los derechos humanos" ${ }^{\prime 34}$. En este sentido, debe darse un uso alternativo de los derechos humanos no desde la afirmación del sujeto abstracto, sino desde

33. Ibíd., p. 561.

34. I. Ellacuría, "El mal común y los derechos humanos", en Escritos filosóficos, Tomo III, óp. cit., p. 449. 
las personas concretas que sufren su violación. Es decir, se le debe dar a las disposiciones jurídicas de derechos humanos un sentido político para ser exigidas en beneficio de las víctimas, de los pobres, de los oprimidos, de las mayorías populares.

La comprensión de la historia como apropiación de posibilidades permite comprender los derechos humanos desde la praxis de los pobres, los excluidos y los oprimidos. Los derechos humanos surgieron principalmente como un instrumento de defensa frente al poder político, con el objetivo de limitar sus posibles abusos e impedir que se reprodujeran los excesos que había cometido durante el antiguo régimen. En ese momento, quienes luchaban eran individuos concretos, en su situación de burgueses, que buscaban condiciones para reproducir su vida. Entonces eran una subjetividad emergente que, a través de la abstracción, logró invisibilizar el conflicto que dio origen a sus derechos, y los pretendieron como producto de la naturaleza humana y no de la praxis. A partir de ahí, los derechos humanos han constituido, en su versión dominante, la peculiar ideología normativa del mundo moderno-burgués. Es importante tener en cuenta que, como señala Nicolau-Coll, "no es lo mismo utilizar los derechos humanos para defenderse de los abusos de las empresas transnacionales o de los Estados (dictatoriales o democráticos) en cualquier lugar del mundo, que utilizarlos para imponer un modelo social, político y económico dado, en este caso del occidente moderno" 35 . Habría que añadir que las grandes mayorías populares, o las minorías discriminadas, han de defenderse no solo de las empresas transnacionales o del Estado, sino de diversas formas de poder que atentan contra la dignidad humana al impedir la producción y reproducción de la vida. En otras palabras, como señala Ellacuría, los derechos humanos deben ser instrumentos para combatir todo tipo de violencia estructural e institucional: "La existencia de mayorías muy por debajo de los niveles que se requieren y son posibles en nuestra época, incluso aunque no hubiera represión positiva, es la prueba de la injusticia de la estructura y de la violencia institucional. La violencia institucional es, así, la violencia originante y la violencia principal" ${ }^{36}$.

Los derechos humanos siempre existen en relación con la sociedad y en función de una concreción del ser humano. Su comprensión desde la teoría hegemónica sostiene la existencia de "derechos" del individuo con total independencia de sus relaciones sociales y de cómo estos se construyen, y además no interesa si dichos derechos se ven afectados si el individuo es indígena, empresario, obrero, blanco, negro, varón, mujer, etc. El contractualismo clásico termina neutralizando la capacidad creativa del ser humano; señala que los individuos

35. A. Nicolau-Coll, "Derechos humanos y diversidad cultural”, Ixtus 57, 2006, p. 31.

36. I. Ellacuría, "La Iglesia y las organizaciones populares en El Salvador", en Escritos políticos, Tomo II, óp. cit., p. 662; y “Comentarios a la Carta Pastoral”, óp. cit., p. 715. 
tienen derechos que pueden exigir a las instituciones del Estado, pero a cambio las personas pierden su capacidad de lucha por la dignidad y la construcción de estructuras para el acceso igualitario a los bienes que satisfagan sus necesidades. Renuncian a esta capacidad de lucha porque le entregan al Estado el poder de construir dichas estructuras, que son edificadas en función de los intereses de los sectores hegemónicos de la nación o del mundo. Además, al darles a los derechos humanos un carácter eterno, racional, universal y natural, se invisibilizan las relaciones humanas conflictivas que dieron origen a la acumulación de ciertos derechos, en este caso, de los llamados de libertad negativa.

En cambio, los derechos humanos en una teoría crítica tienen su fundamento en la praxis de los pueblos en busca de justicia, de mejores condiciones de vida que les permitan producir y reproducir su vida. En la situación mundial actual, si realmente queremos tomarnos en serio la justicia, es imprescindible asumir una fundamentación de estos derechos desde la praxis popular y pensarlos desde el-lugar-que-da-verdad, como nos lo propone Ellacuría. Así, los derechos humanos no deben comprenderse solo en función de una sociedad institucionalizada donde con orden se expresan los intereses - eso sí, solo los intereses que se consideran "legítimos"-, sino como un espacio conflictivo donde subjetividades emergentes luchan por mejores condiciones de vida. De lo contrario, los derechos humanos se convierten en un elemento ideológico que, si bien en su momento nacieron como producto de una subjetividad emergente, una vez que se hace del poder, impide que otros sujetos realicen procesos de lucha e intenta dar por terminada toda novedad histórica. En este contexto, por ejemplo, Ellacuría interpreta desde los pobres y su praxis de liberación un derecho humano clásico, es decir, le da un uso alternativo: "El derecho a la existencia de las organizaciones populares es un derecho fundamental, reconocido como tal universalmente y amparado por nuestra Constitución y por nuestros compromisos (...) No se trata sólo de un derecho general de los hombres a unirse y organizarse para lograr fines honestos, sino del derecho mucho más urgente que tienen los desposeídos e injustamente oprimidos a hacer valer sus derechos más fundamentales, que de otra manera se ven permanente, estructural y coyunturalmente conculcados" ${ }^{137}$. En otras palabras, Ellacuría piensa que ciertos derechos nacidos de la modernidad deben contemplarse en la construcción de un nuevo espacio político que posibilite superar democracias de baja intensidad, procedimentalistas y formalis$\operatorname{tas}^{38}$, que en los países latinoamericanos son utilizadas para legitimar los intereses privatistas de las clases sociales altas y de las empresas transnacionales, para dar paso a democracias donde se reconozcan nuevos derechos desde las luchas

37. I. Ellacuría, "El papel de las organizaciones populares en la actual situación del país", en Escritos políticos, Tomo II, óp. cit., p. 737.

38. Cfr. B. de Sousa Santos, Democratizar la democracia. Los caminos de la democracia participativa, Fondo de Cultura Económica, México D. F., 2002, p. 70. 
sociales que reivindican necesidades humanas ${ }^{39}$. Por eso, es incorrecto ver en la lucha por la transformación de las estructuras sociales una reivindicación exclusiva de los derechos sociales y un desprecio por los otros tipos de derechos. Los llamados derechos de libertad y participación pueden ser medios para satisfacer necesidades tan importantes como los derechos económicos, sociales y culturales, y además pueden ser complementarios; lo importante es su historización, es decir, verificar el para qué se usan y el por quién se utilizan. Se trata de asumir el discurso de los derechos humanos y darles un uso alternativo a favor de los pobres $^{40}$. Por ejemplo, Ellacuría consideraba un crimen contra la democracia salvadoreña la no legalización de las organizaciones campesinas, a las que el Gobierno calificaba de comunistas, desestabilizadoras y terroristas, no sólo por tratarse de una violación al derecho constitucional de organización y de libertad de asociación, sino porque consideraba que la organización campesina era una respuesta histórica a la violencia institucionalizada. Al contrario de lo que afirmaba el Estado, la participación popular significaba una de las salidas fundamentales frente a la violencia estructural e institucionalizada que azotaba al país ${ }^{41}$.

Así, los derechos humanos consisten, desde el hacerse cargo de la realidad, en la construcción de espacios de lucha que logren subvertir las injusticias y las opresiones que impiden la satisfacción de necesidades de los pueblos de todo el planeta. Se trata de procesos de todo tipo, no sólo normativos, como parecerían afirmar las teorías liberales y ciertas corrientes analíticas, sino también procesos económicos, políticos, culturales, sociales, que vayan encaminados a la liberación integral de las personas. Procesos que permitan la transferencia de poder a los sectores marginados de las sociedades, para que a través de su empoderamiento puedan hacer efectivo aquello que se predica formalmente como derecho humano desde su propia particularidad.

\section{Ellacuría y la tradición hispanoamericana de los derechos humanos}

En conexión con todos los puntos arriba descritos, podemos señalar que Ellacuría puede ser inscrito en la tradición hispanoamericana de los derechos humanos (THDH). Esta tradición tiene sus orígenes históricos en la defensa de los pueblos indios realizada, entre muchos otros, por fray Bartolomé de las Casas y fray Alonso de la Veracruz. Esta tradición se diferencia de las tradiciones liberales por varias razones: mientras éstas están basadas en el individuo abstracto,

39. I. Ellacuría, "El papel de las organizaciones populares en la actual situación del país", óp. cit., p. 739.

40. Cfr. J. A. de la Torre Rangel, El derecho como arma de liberación en América Latina. Sociología jurídica y uso alternativo del derecho, CENEJUS-UASLP, San Luis Potosí, 2006, pp. 99-158.

41. Cfr. I. Ellacuría, "La Iglesia y las organizaciones populares en El Salvador", óp. cit., p. 664 . 
la THDH parte de las víctimas concretas del sistema; las tradiciones liberales suelen basarse en una concepción individualista del ser humano, mientras que la THDH se basa en la persona como ser individual y comunitario; las tradiciones liberales nacieron limitadas a las fronteras del Estado-nación, mientras que la THDH siempre ha tenido una visión mundializada del problema de la opresión; las tradiciones liberales tienen su origen en las luchas burguesas y han sido funcionales al capitalismo, mientras que la THDH supone el uso del derecho y de los derechos humanos para la liberación de los pobres; las tradiciones liberales han sido dominantemente monoculturales, mientras que la THDH es pluricultural.

Ahora bien, son diversas las razones que sustentan la importancia de asumir la THDH para el pensamiento latinoamericano de la liberación. En primer lugar, significa ubicar el tema de derechos humanos en aquellas teorías y praxis que el pensamiento de la liberación - sobre todo, la filosofía y la teología - ha asumido como sus antecedentes, es decir, como el primer encuentro con la alteridad de la víctima y la lucha por su liberación. Además, es asumir una preocupación por recuperar la historia de las ideas filosóficas que existe en las distintas regiones de América Latina y el Caribe. A partir de la particular situación sociohistórica, se ha buscado una interpretación del pasado, que se piense desde las luchas del presente, con la clara intencionalidad de delinear un futuro construible y compartible colectivamente.

En segundo lugar, las características de esta tradición son más acordes con la liberación de los pobres en las propias circunstancias de América Latina dentro del sistema-mundo. Podemos citar las palabras de Cerutti en este sentido: "Quizá no en todo momento histórico la filosofía necesita volverse sobre su pasado, pero sí en situaciones de subordinación o marginación cultural como las que nos ocupan, situaciones en las cuales la memoria propia ha tendido a ser borrada y no se sabe a ciencia cierta dónde se está. (...) Volverse sobre lo pensado, recuperar críticamente la memoria propia del pensamiento es necesario para poder establecerse una tradición, acumular elementos, deslindar estilos, precisar contenidos, acompañar esfuerzos, dejar vías muertas de lado, no perder aliento. Para no permanecer, en suma, aplastado y agobiado por una tradición desconocida, pero subrepticiamente operante" ${ }^{42}$.

La tercera razón es que a través de esta tradición las luchas de liberación latinoamericanas pueden hablar de derechos humanos sin asumir forzosamente sus matrices eurocéntrica, monocultural, individualista y burguesa. Desde las propias circunstancias sociohistóricas de América Latina, la lucha por la dignidad humana ha adquirido un sentido pluricéntrico, pluricultural, comunitario y popular; a partir de estas características, los derechos de las personas se han pen-

42. H. Cerutti y M. Magallón, Historia de las ideas latinoamericanas, ¿disciplina fenecida?, Casa Juan Pablos, México D. F., 2003, p. 75. 
sado desde las clases sociales más desfavorecidas, desde abajo, y en contextos concretos, evitando así la formulación de abstracciones respecto al ser humano. Una última razón consiste en que esta tradición recupera experiencias que han sido invisibilizadas y, por lo tanto, desperdiciadas por lo monocultural del saber jurídico que sólo reconoce las tradiciones noratlánticas (inglesa, francesa y estadounidense) como las únicas que pueden considerarse defensoras y promotoras de derechos humanos.

En este sentido, cuando Ellacuría afirma que "los derechos humanos deben ser primariamente derechos de los oprimidos, pues los opresores no pueden tener derecho alguno, en tanto que opresores, y a lo sumo tendrán el derecho a que se les saque de su opresión. Sólo haciendo justicia a los pueblos y a las clases oprimidas se propiciará su auténtico bien común y los derechos humanos realmente universales" ${ }^{43}$, se ubica de lleno en la THDH.

En conclusión, podemos señalar que una teoría crítica de los derechos humanos nos lleva a sostener, siguiendo a Ellacuría, que "[m]ientras haya pobres, la liberación vendrá de los pobres. Cuando deje de haberlos, porque ha sido superado mundialmente el estado de satisfacción de las necesidades básicas y haya sido superada también la desigualdad injusta" ${ }^{44}$. Es decir, mientras existan pobres, los derechos humanos deberán ser constantemente reinventados, renovándolos dentro de la praxis de liberación, para evitar su ideologización y utilización como instrumentos de opresión.

43. I. Ellacuría, "Historización del bien común y de los derechos humanos en una sociedad dividida", en Escritos filosóficos, Tomo III, óp. cit., p. 223.

44. I. Ellacuría, "En torno al concepto y a la idea de liberación", óp. cit., p. 645. 